\title{
INSPEÇÃO TÉCNICA COMO DISPOSITIVO DE FORMAÇÃO DE PROFESSORES: ESTRATÉGIA DE PRODUÇÃO DE UM MODELO ESCOLAR EM MINAS GERAIS
}

\author{
Rogéria Moreira Rezende Isobe \\ Universidade Federal do Triângulo Mineiro, Brasil.
}

\section{$\cos 80$}

\section{Resumo}

Este artigo analisa o serviço da inspeção técnica do ensino como estratégia de produção de um modelo escolar em Minas Gerais no âmbito da Reforma João Pinheiro. No processo de constituição de um sistema educacional pautado no referencial da pedagogia moderna, os inspetores técnicos se configuraram como modeladores do ensino e buscaram capacitar os professores para o adequado exercício de novos métodos, dando-lhes a ver, por meio de aulas exemplares, modos de praticá-los. Nessa conjuntura, o inspetor técnico atuava sobre a prática docente, a partir de um lugar de poder determinado, o lugar de um intérprete autorizado cuja ação visava a aproximar as práticas dos professores das regras estabelecidas na conformação de um determinado modelo escolar de educação em Minas Gerais.

Palavras-chave: inspeção técnica do ensino, estratégias, modelo escolar.

\section{TECHNICAL INSPECTION AS A TEACHERS' FORMATION DEVICE: PRODUCTION STRATEGY OF A SCHOOL MODEL IN THE STATE OF MINAS GERAIS}

\begin{abstract}
This article analyses the service of technical inspection as a production strategy of a school model in the State of Minas Gerais under the João Pinheiro Reform. Within the process of constitution of an educational system guided by the reference of modern pedagogy, the technical inspectors were education shapers, enabling teachers to the proper exercise of new methods, making visible through exemplar classes the correct way to practice these new methods. Under this perspective, the technical inspector acted on the teaching practice, from an established place of power, the place of an authorized interpreter whose action intended to harmonize the teacher's practices with the rules determined in shaping of a certain school model in the State of Minas Gerais.

Key-words: technical inspection of education, strategies, school model.
\end{abstract}




\section{DISPOSITIVO DE INSPECCIÓN TÉCNICA COMO LA FORMACIÓN DEL PROFESORADO: UNA ESTRATEGIA PARA LA PRODUCCIÓN DE UNA ESCUELA MODELO EN ESTADO DE MINAS GERAIS}

Resumen

Este trabajo analiza el servicio de inspección técnica de la educación como una estrategia para producir un modelo de escuela en Minas Gerais inserta en la Reforma de João Pinheiro. En el proceso de creación de un sistema educativo guiado por la referencia de la pedagogía moderna, los inspectores técnicos se configuran como modeladores de la enseñanza, que permiten a los profesores el ejercicio adecuado de los nuevos métodos, dándoles ver, a través de clases ejemplares, los modos de practicarlos. En este contexto, el inspector técnico que actúa en la práctica docente, desde un lugar de poder determinado, el lugar de un intérprete autorizado, cuya acción tenía por objeto armonizar las prácticas de los profesores con las reglas establecidas en la conformación de un tipo particular de modelo de escuela en Minas Gerais.

Palabras-clave: inspección técnica de educación, estrategias, escuela modelo.

\section{DISPOSITIF DE CONTROLE TECHNIQUE DANS LA FORMATION DES PROFESSEURES: UNE STRATÉGIE POUR LA PRODUCTION D'UNE ÉCOLE MODĖLE DANS L'ÉTAT DE MINAS GERAIS}

\section{Résume}

Cet article analyse le service d'inspection technique de l'éducation comme une stratégie pour produire un modèle d'école dans l'état de Minas Gerais au sein de la réforme João Pinheiro. Dans le processus de mis en place d'un système éducatif guidé par le référence de la pédagogie moderne, les inspecteurs techniques sont configurés comme de faiseurs d'enseignement, en permettant aux professeurs le correct exercice de les nouvelles méthodes, en donnant à voir, à travers des classes exemplaires, modes de leur pratique. À ce stade, l'inspecteur technique avait une action sur la pratique de l'enseignement, à partir d'un déterminé lieu de pouvoir, le lieu d'un interprète autorisé dont l'action était destinée à harmoniser les pratiques des professeurs avec les régles établies dans la conformation d'une certaine type de modèle scolaire dans l'état de Minas Gerais.

Mots-clé: inspection technique de l'éducation, stratégies, modèle scolaire. 


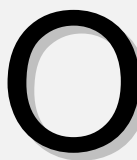
texto aborda uma temática que tem sido objeto de interesse nos estudos e pesquisas que tenho desenvolvido ${ }^{1}$ e apresenta resultados de um processo investigativo iniciado nos cursos de mestrado e doutorado (Isobe, 2004; 2008), que analisa o serviço de inspeção como dispositivo central de constituição e consolidação de um determinado modelo escolar no âmbito da Reforma João Pinheiro, em Minas Gerais, implementada em 1906.

A análise do corpus empírico - relatórios de inspeção, mensagens presidenciais, relatórios do secretário do Interior e regulamentos do ensino - foi balizada pelas asserções de Marta de Carvalho a respeito do estatuto central da pedagogia moderna na constituição do modelo escolar paulista caracterizado pelo primado da visibilidade (Carvalho, 1989; 2000a; 2000b; 2001; 2003; 2006; 2011).

$\mathrm{Na}$ perspectiva delineada por Marta de Carvalho, a inspeção escolar ganha um sentido específico se compreendida como peça de uma engrenagem movida pela lógica da reprodução de bons moldes fundamentada numa concepção de pedagogia prática, na qual "a arte de ensinar é prescrita como boa imitação de práticas modelares" (Carvalho, 2001, p. 145). Nessa lógica, o modelo escolar se reproduzia por meio de dispositivos "materializados nas demonstrações da escola modelo e no exercício da inspeção escolar" (Carvalho, 2000a, p. 225), capazes de promover a visibilidade das práticas pedagógicas que se pretendia uniformizar.

A propósito, Carvalho (2011) sustenta que as práticas "de uniformizar e homogeneizar métodos e processos de ensino não funcionam apenas como dispositivos de controle", mas adquirem um significado específico quando analisadas no campo normativo da pedagogia moderna, estruturada sob o primado da visibilidade: "passam a designar dispositivos de produção do aparelho escolar paulista" e funcionam como "ingredientes da própria lógica que põe em cena a tão propalada reprodução de bons moldes" (p. 190).

A utilização da noção de modelo escolar como ferramenta analítica implica compreendê-lo como uma articulação possível de elementos no conjunto de "dispositivos científicos, religiosos, políticos, pedagógicos que definiram a modernidade como sociedade da escolarização" (Carvalho, 2003, p. 316), ou seja, a fertilidade analítica da noção de modelo no campo da pesquisa historiográfica implica estabelecer relações entre os elementos "conferindo-Ihes sentido no interior de um campo semântico determinado" (Carvalho, 2011 p. 190).

Com base nos aportes conceituais dessa autora, o serviço da inspeção técnica, instituído com a Reforma João Pinheiro em Minas Gerais, é analisado como peça de uma engrenagem construída como estratégia de constituição do modelo escolar pautado no referencial da pedagogia moderna, "cujo segredo é a boa imitação de modelos" (Carvalho, 2011, p. 191), alicerçada sobre a lógica da reprodução do modelo escolar por meio de dispositivos de produção visibilidade e imitabilidade das práticas escolares e de homogeneização do ensino.

\footnotetext{
1 Os estudos e investigações são desenvolvidos atualmente na linha de pesquisa História da Educação do Núcleo de Estudos e Pesquisas em Política, História, Espaço, Educação e Sociedade, da UFTM, e na linha de pesquisa Instituições, poder e cultura do Grupo de Pesquisas História Cultural da escola e dos saberes pedagógicos: impressos e modelos culturais, na Unifesp.
} 


\title{
A instituição da Inspetoria Técnica do Ensino: estratégia de produção de um modelo escolar em Minas Gerais
}

Em 1906, sob a presidência de João Pinheiro da Silva, o governo estadual de Minas Gerais pôs em andamento ampla reforma educacional: a lei n. 439, de 28 de setembro de 1906, regulamentada pelo decreto n. 1.960 , do mesmo ano, autorizou alterações no ensino primário e normal. A configuração do sistema de ensino que se instituía colocou em cena os dispositivos constitutivos do modelo escolar: a Escola Normal Modelo, paradigma para os estabelecimentos equiparados; o Grupo Escolar, signo da modernidade pedagógica e instituição modelar na qual se exibiam práticas exemplares; o método intuitivo, expressão máxima da renovação pedagógica dado a ver, primeiramente, nos grupos escolares de Belo Horizonte. Articulando-se a esses elementos, cria-se a Inspeção Técnica do Ensino, com vistas à consolidação do modelo escolar.

$\mathrm{Na}$ capital mineira, centro irradiador do movimento de modernização do ensino (Faria Filho, 2000; Vago, 2002), são erigidas instituições modelares que se configuram como lugares para se observar como se faz para aprender a fazer:

Convém que durante as férias seja chamado à capital certo número de professores para assistirem à execução leal do programa não só nos grupos escolares como nas escolas isoladas que aqui já funcionam naturalmente com todas as exigências. Esta idéia é sugerida pela vinda espontânea nas férias do ano passado, de grande número de professores que desejaram assistir as aulas do primeiro grupo que, então, apenas se ensaiava e da escola isolada que começava a funcionar para servir de modelo às demais do Estado. (Minas Gerais. Relatório do secretário do Interior, 1907 p. 42)

Para concretização das mudanças pedagógicas, os representantes do governo salientavam a necessidade de formação do professorado, pois, a instituição dos grupos escolares, como expressão de moderna e renovada organização da escola primária, pressupunha a remodelação do campo escolar e das práticas de ensino na sala de aula. A Escola Normal Modelo da Capital e os institutos a esta equiparados encarregar-se-iam da formação dos novos docentes, mas era preciso investir na formação dos professores que já atuavam nas escolas primárias, com vistas a extirpar hábitos maus e inveterados e capacitar os professores para a prática dos novos métodos. Tal era a preocupação do presidente João Pinheiro:

\begin{abstract}
A reforma tem que lutar com os hábitos maus e inveterados, com um professorado que não estava suficientemente preparado para a prática dos novos métodos e por isso será preciso ainda, e por tempos, uma ação intensa e mantida, premunidos todos contra os desânimos vis, de que as infelizes retrogradações são filhas. (Minas Gerais. Mensagem do Presidente do Estado, 1907, p. 5)
\end{abstract}

Para executar essa ação sobre a prática docente os reformadores procuraram imprimir nova feição à inspeção escolar, de maneira a superar as funções de fiscalização meramente burocráticas do cargo, como se realizava até então. Desta forma, o sistema de inspeção do ensino foi divido em dois ramos: técnico e administrativo. Composto pelos inspetores técnicos e pelos inspetores escolares, organizava-se em um conjunto diverso 
de funções e agentes que tinham como tarefa operacionalizar mudanças na organização pedagógica e administrativa do ensino.

A inspeção administrativa era realizada pelos inspetores escolares ou municipais, cargos não remunerados e confiados, em geral, a promotores de justiça que exerciam, além de sua profissão, a fiscalização das escolas nos assuntos gerais relacionados às questões burocráticas e administrativas. O caráter predominantemente fiscalizador que marcava o serviço da inspeção desde o século 19, em Minas Gerais, se mantém no ramo da inspeção administrativa que "como antigamente, continua a ser desempenhada gratuitamente por cidadãos de livre nomeação do governo que têm funções meramente fiscais" (Minas Gerais. Relatório do Secretário do Interior, 1909, p. 22).

A Inspeção Técnica do Ensino ${ }^{2}$, instituição nova, remunerada e criada com a reforma de 1906, era realizada por profissionais dedicados exclusivamente ao serviço da inspeção escolar com atuação direta no fazer do professor. O Regulamento da Instrução Primária e Normal do Estado de Minas Gerais estabelecia que os inspetores técnicos deveriam prestar assistência técnica aos docentes para que o programa fosse fielmente praticado sendo necessário, para tanto, que os técnicos ministrassem instruções aos professores e assistissem o funcionamento da aula para apontar os defeitos e as faltas indicando o que seria preciso modificar na prática do professor.

Seria imprescindível, também, "mostrar praticamente qual a verdadeira execução do programa" (Minas Gerais. Regulamento da Instrução Primária e Normal do Estado de Minas Gerais, 1906, p. 47). Além das instruções verbais e aulas exemplares dadas pelos inspetores, tais funcionários deveriam deixar orientações por escrito para o professor no termo de visita cuja cópia deveria ser enviada à Secretaria, anexa ao relatório.

Para realizar suas funções os técnicos itinerantes deveriam apresentar "grande número de variados conhecimentos pedagógicos e de cada uma das disciplinas do programa de ensino" para levar "aos diversos pontos do estado a convicção ao professorado da necessidade e utilidade do emprego dos novos métodos de ensino, indicando-lhes os meios a seguirem na sua execução" (Minas Gerais. Relatório do Secretário do Interior, 1909, p. 415).

Mas quem seria esse inspetor conhecedor de uma técnica capaz de imprimir um novo ensino nas escolas? Que saber técnico é esse e como ele foi adquirido? $O$ secretário Carvalho Brito esclarece que

grande número dos inspetores técnicos foi tirado dos professores em disponibilidade das Escolas Normais suspensas e não são menos competentes os que não eram professores. Levam, pois, para a inspeção, o prestígio alcançado na sua posição anterior. (Minas Gerais. Relatório do Secretário do Interior, 1907, p. 42)

O secretário do Interior recorre às noções de competência e prestígio para construir um lugar de saber/poder dos inspetores técnicos sobre os professores, ou seja, a experiência como formadores de professores os legitimava como modeladores da prática docente. Nessa ótica, enquanto a Escola Normal Modelo da Capital e os institutos a esta

\footnotetext{
${ }^{2}$ O decreto n. 3.191, de 9/6/1911, substituiu a denominação de "inspetor técnico" por "inspetor regional". A partir de então, a inspeção passou a ser designada pelas autoridades educacionais como "regional", "técnica" ou "especial".
} 
equiparados encarregar-se-iam da formação dos novos docentes, os inspetores técnicos deveriam intervir na prática dos professores que já atuavam nas escolaspara extirpar "hábitos maus e inveterados" (Minas Gerais. Mensagem do Presidente do Estado, 1907, p. 5) e formar os professores para a prática da nova educação primária.

A inspetoria técnica constitui-se, assim, em um corpo de profissionais da educação que se define por uma competência técnica supostamente conformada e controlada por uma autoridade central representada pelos agentes da Secretaria do Interior, ou seja, o saber técnico é definidor do profissionalismo do inspetor e, portanto, de sua autoridade e poder para atuar e interferir na prática docente. Nessa ótica, a autoridade dos inspetorestécnicos Ihes era conferida por um determinado saber técnico, especializado, científico e, portanto, pretensamente neutro com "insuspeição nas informações que derem" (Minas Gerais, Relatório do secretário do Interior, 1914, p. 292).

A avaliação dos professores era realizada pelos inspetores por meio das informações registradas nos relatórios cujos dados eram arquivados "em um livro reservado existente na Secretaria" (Minas Gerais, Relatório do Secretário do Interior, 1909. p. 415). Recorrendo-se a eles, os agentes estatais tinham o conhecimento de "todo o conjunto de qualidades pedagógicas que constituem a competência profissional dos bons professores" bem como "os defeitos corrigíveis ou sanáveis dos pouco preparados" e também "a inaptidão invencível dos estacionários quanto ao preparo ou inadaptáveis às exigências atuais do ensino para os quais o regulamento em vigor instituiu o processo de desqualificação" (Minas Gerais, Relatório do Secretário do Interior, 1913, p. 293).

Ao avaliar os docentes, o inspetor anotava suas observações, solicitava prêmios de viagem aos melhores professores, indicava aqueles que não deveriam "ser aproveitados pelo governo estadual" e informava sobre os professores que apresentavam os requisitos necessários para assumir os cargos de direção dos grupos escolares, conforme determinação da Secretaria do Interior (Minas Gerais, Relatório do Secretário do Interior, 1913, p. 295).

Além dos relatórios ordinários quinzenais com informações sobre os professores e suas práticas, os inspetores também avaliavam os docentes por meio de boletins reservados com base nos critérios definidos pela administração central: inteligência, preparo, aptidão didática, moral, boa fama, emprego do método intuitivo, adoção da caligrafia vertical e método adotado no ensino de leitura. O relatório do secretário do Interior, correspondente ao exercício de 1913, apresenta o resultado da avaliação dos professores julgados ou classificados pela inspeção:

Apuradas, com relação a mil e duzentos e oitenta e três docentes (estaduais, municipais e particulares), as diversas notas dos últimos boletins reservados de abril de 1912 a março de 1913, com exclusão daqueles cujos dizeres não são precisos ou são deficientes, verificou-se que os professores assim julgados ou classificados pela inspeção distribuem-se do seguinte modo: 536 são educadores de reconhecida competência e capazes da execução autonômica dos programas oficiais, desde que se Ihes não oponha a deficiência de material didático, fato comum em localidades desprovidas de meios de comunicação; 452 são professores simplesmente bons, isto é, a quem falta algum requisito pedagógico para colocação em primeiro plano no magistério; 185 são professores sofríveis ou de poucos requisitos, necessitados de assistência, 
aguardando o governo $\circ$ resultado desta para providenciar na conformidade do regulamento; 110 são maus docentes e, como tais, sujeitos desde que não se afastem espontaneamente do magistério, ao processo de desclassificação se forem funcionários do Estado, e, se particulares ou municipais, às providências dos arts 406 e 407 do regulamento geral da instrução. ${ }^{3}$ (Minas Gerais, Relatório do Secretário do Interior, 1913, p. 294)

Dentre todos os predicados desejados para o exercício do magistério primário, os de cunho pedagógico assumiam preponderância na classificação docente realizada pela administração central, evidenciando que os melhores professores eram os que apresentavam reconhecida competência que se referia à capacidade de execução autonôma dos programas oficiais, o que implicava na desqualificação dos saberes e práticas que se diferiam dos referenciais que fundamentava os referidos programas.

Além de informações sobre as práticas dos professores estaduais, as quais estavam sujeitas à observância rigorosa de quanto preceitua o regulamento geral da instrução, os docentes das escolas municipais e particulares também tinham sua autonomia cerceada. Em seus relatos, os inspetores foram incumbidos de apresentar "as informações de que a Secretaria carece para conhecer todo o pessoal de professores existentes no Estado, não só os públicos, como os particulares e municipais" (Minas Gerais. Relatório do secretário do Interior, 1909, p. 25). Desta forma, o "professorado não oficial" não tinha "liberdade ampla até o ponto de colidir o seu regime com o das oficiais" para que seus modos de ensinar não se tornassem "perniciosos contra o aperfeiçoamento da instrução do povo" (Minas Gerais. Relatório do Secretário do Interior, 1913, p. 293).

A atuação da inspetoria técnica se configurava a partir de um duplo movimento: modelar as práticas escolares e relatar as mudanças realizadas, o que era feito por meio de relatórios quinzenais, que deveriam ser encaminhados aos órgãos centrais. A produção de um campo de visibilidade sobre as práticas escolares, por meio dos relatórios quinzenais, tinha o propósito de garantir a ação reguladora do governo com vistas à conformar os saberes e práticas de tais funcionários, que só recebiam 0 pagamento de seus salários mediante o encaminhamento de tais documentos aos órgãos centrais.

As informações contidas nos relatórios balizavam as ações da Secretaria do Interior que buscava regrar, também, a prática da inspeção por meio da expedição de circulares e ofícios com orientações sobre o ensino. No período de 1911 a 1912, por exemplo, foram expedidos aos inspetores técnicos 317 ofícios e circulares contendo ordens e detalhes de serviço (Minas Gerais. Relatório do Secretário do Interior, 1912). Uma dessas circulares, mencionada no relatório do inspetor Antônio Batista dos Santos, evidencia a importância das aulas exemplares como práticas de modelização do trabalho docente:

\footnotetext{
${ }^{3}$ Quanto aos artigos referidos, o Regulamento de 1911 determina: Art. 406. "Serão fechados: I - os estabelecimentos e escolas em que professarem pessoas proibidas e os dirigidos por elas; II - os anti-higiênicos; III - os prejudiciais à ordem pública; IV - aqueles nos quais se praticarem crimes ou atos contrários à moral e aos bons costumes." Art. 407. "Também não poderão funcionar, equiparados aos do artigo antecedente, os estabelecimentos e escolas cujo ensino prejudicar à higiene mental das crianças". Art. 408. "Ao Secretário do Interior compete determinar o fechamento dos estabelecimentos particulares" (Regulamento geral da Instrução do Estado de Minas Gerais, decreto n. 3.191, de 9 de junho de 1911, Belo Horizonte: Imprensa Oficial do Estado, 1911).
} 
Inspecionei as escolas de Uberabinha, nas quais procurei tornar efetivas vossas recomendações constantes na circular de 4 de janeiro deste ano. Iniciei meus trabalhos pela escola feminina de d. Alvina de Souza, normalista pela escola equiparada da cidade de Uberaba. Foi meu primeiro cuidado organizar as alunas em turmas correspondentes aos três anos do curso, que tantos são os que a escola conta atualmente. Seguidamente, assumi a direção dos exercícios escolares e fui, para bem dizer, o professor durante as quatro horas regulamentares. [...] E, assim revezando no ensino às classes, consegui esgotar todas as disciplinas do dia, dentro do horário regulamentar, e convenci a professora da perfeita exeqüibilidade do programa, bem como da eficácia dos processos de ensino atualmente adotados. [...] No dia seguinte, repeti minha visita e fiz o mesmo trabalho do dia anterior, mas, desta vez, seguindo o diário organizado de véspera pela própria professora. Solicitei a presença do inspetor escolar municipal, a fim de que se tornem efetivas em minha ausência as instruções que forneci. [...] No dia seguinte, ao terminar meus trabalhos de remodelação da escola e sistematização do ensino, lancei no livro de termos instruções sobre o ensino de todas as disciplinas escolares e sobre sua radical reorganização, retirando-me convicto de ter fornecido as bases para sua remodelação. (Minas Gerais. Relatório de Inspeção. Uberabinha, 18 de maio de 1909)

Na lógica do modelo escolar baseado na prática, no ver fazer, cabia aos inspetores técnicos percorrer as escolas distribuídas pelo território mineiro para adequar a cópia ao modelo, capacitar os professores para o adequado exercício dos novos métodos e processos de ensino advogados pela Reforma, dando-lhes a ver, por meio de aulas exemplares, modos de praticá-los, pois "a arte de ensinar torna-se largamente dependente da capacidade de observar para imitar" (Carvalho, 2001, p. 141).

Os modeladores do ensino faziam, assim, a mediação entre as estratégias de modelagem das práticas culturais, segundo seus princípios instituintes, e as práticas alvo dessas estratégias de modelagem: a prática docente. Nesse sentido, a inspeção técnica do ensino pode ser entendida como dispositivo de formação docente que buscava modelar a prática do professor primário no seu próprio local de trabalho: a sala de aula.

A partir da possibilidade interpretativa delineada por Marta Carvalho, a análise do modelo escolar que balizou as iniciativas republicanas de institucionalização da escola em Minas Gerais indica a configuração de conjunto de elementos articulados pelos preceitos de uma pedagogia moderna entendida como arte de ensinar.

Nesse modelo, o inspetor técnico, respaldado e autorizado por uma suposta competência técnica, atuava sobre o processo educacional e, sobretudo, sobre a prática docente a partir de um lugar de poder determinado, o lugar de um intérprete autorizado cuja ação visava a implantar bons moldes de ensino para aproximar as práticas dos professores das regras estabelecidas na conformação do modelo escolar mineiro.

Tomando como ferramenta analítica o conceito de estratégia indicado por Certeau $(1990)^{4}$ é possível, ainda, flagrar a inspetoria técnica e a própria Secretaria do Interior como lugares de poder que, no âmbito de uma política educacional caracterizada pela ação reguladora e centralizadora do governo, institui uma hierarquia de autoridade entre

\footnotetext{
${ }^{4}$ Para Certeau (1990) as estratégias remetem a práticas cujo exercício pressupõe um lugar de poder e designa dispositivos de normatização e modelização que, desse lugar de poder em que são produzidos, regulam práticas que se inscrevem em um território que lhes é exterior.
} 
os agentes educativos. Nesse processo, os saberes e práticas escolares são produzidos, por autores diferenciados e hierarquicamente situados.

A hierarquia estabelecida está em relação direta com um saber legitimado pelos preceitos da moderna pedagogia que delimitava a competência dos sujeitos e atravessava as práticas escolares, produzia determinadas formas de relação entre os mesmos: os inspetores técnicos subordinavam-se à autoridade central, Secretaria do Interior, e os professores e diretores de grupos escolares subordinavam-se à competência técnica dos inspetores. Tais agentes tinham autoridade tanto para modelar a prática dos professores, quanto para constituir, a respeito deles, um julgamento capaz de medir suas qualidades, méritos e defeitos, classificando-os como bons ou maus docentes quanto aos seus saberes, suas práticas, enfim, sua competência profissional.

\section{Os limites da inspeção técnica como dispositivo de formação docente}

A análise dos documentos permite observar a emergência de um juízo que evidenciava os limites da inspeção técnica como dispositivo de formação docente e, conseqüentemente, como dispositivo de consolidação e expansão do modelo escolar. Observa-se que, para os inspetores, um dos grandes entraves para o sucesso de suas intervenções na prática docente era a falta de um repertório de conhecimentos básicos ao professor, para que este pudesse tirar proveito dos serviços da inspeção técnica do ensino.

A propósito, o inspetor Alceu de Souza Novaes relata que o diretor do Grupo Escolar do município do Prata, que exercia também a docência na instituição, não conhecia as matérias a lecionar:

O diretor normalista Pedro Nery não se adapta ao cargo que ocupa, embora se esforce por bem desempenhá-lo. É autoritário, não conseguindo dar uma ordem qualquer sem magoar as professoras. Tal é, pelo menos, do que as mesmas se queixam. Não conhece as matérias a lecionar e não tem prática do ensino intuitivo. (Minas Gerais, Relatório de Inspeção. Prata, 24 de fevereiro de 1911)

O inspetor iria encontrar o mesmo problema em outras ocasiões como, por exemplo, na visita à escola isolada regida pela professora Áurea Guimarães Machado, na cidade de Prata: "Assistência Técnica - a professora desconhece parte da matéria a transmitir. Durante dois dias prestei-lhe assistência sobre todos os pontos do programa" (Minas Gerais. Relatório de Inspeção. Prata, 13 de março de 1911).

No mesmo relatório o inspetor sinaliza o problema da falta de conhecimento das matérias de ensino em outra escola visitada: "Escola estadual masculina a cargo do professor Arnold de Vasconcellos [...] o professor ignora parte das matérias a lecionar. Prestei-lhe assistência sobre todos os pontos em que julguei necessário" (idid).

Esse repertório de conhecimentos básicos, em alguns casos, evidencia-se no conhecimento das matérias a ensinar e, em outros, em questões básicas para se atuar num universo cultural da escola, em que escrever, ler e falar corretamente são requisitos essenciais. O inspetor Alceu Souza Novaes critica a ignorância do professor como um grande problema para o ensino: 
O professor Hormizdas José Ferreira é dedicado em extremo, porém, infelizmente, é atrasadíssimo. Leciona leitura, escrita e contas (as quatro operações fundamentais) [...] A leitura é péssima. Os alunos fazem composições crivadas de erros que o professor não corrige por não saber fazê-lo. Para mostrar a V. Exa. a que pessoas recorrem naqueles ermos os pais ciosos da instrução de seus filhos, transcrevo aqui umas linhas tiradas de um caderno do professor: "cecullos tem cem annos, annos tem doze mezes, mezes tem trinta dias, argum tem trinta e um", etc. Deixo de grifar as palavras erradas, porque são quase todas. (Minas Gerais. Relatório de Inspeção, Uberaba, 5 de maio de 1911)

Alguns professores são criticados pela suposta ignorância, que os tornava incapazes de tirar proveito das aulas exemplares ministradas pelos inspetores. Uma boa imitação das práticas exemplares, dadas a ver pelas intervenções dos inspetores, requeria a capacidade de adaptar os procedimentos metodológicos encenados à variedade dos conteúdos a ensinar e à diversidade de situações do cotidiano escolar. $A$ posse prévia, pelo professor, de um determinado repertório pedagógico e cultural era, assim, condição necessária do bom sucesso das intervenções remodeladoras dos inspetores.

O inspetor Antônio Batista dos Santos também relata os entraves do trabalho técnico na remodelação das escolas:

Lancei as bases para a integral sistematização do ensino nas escolas de Uberabinha, mas, como tenho observado sempre que me esforço nessa ordem de trabalho, a rotina e o fraco preparo dos professores, com honrosas exceções, se mantêm como duas formidáveis barreiras aos técnicos do ensino. Os atuais educadores, habituados à antiga liberdade originada da não execução dos regulamentos passados, recebem constrangidos o inspetor técnico e encaram essa autoridade como um espécie de algoz, desde que lhes lembre o dispositivo da lei e lhes peça o seu cumprimento. Outros, ao receberam a visita da inspeção, fazem uma espécie de encenação de ordem e disciplina, asseio e métodos, voltando ao desleixo habitual, à sombra dos processos antiquados e rotineiros, logo que sintam a ausência do técnico. Apoiados nos preconceitos que ainda assoberbam os responsáveis pela educação da infância, os quais de ordinário têm recebido com certa repugnância as inovações no ensino das escolas, na prolongada ausência da autoridade técnica e no desconhecimento que, com honrosas exceções, têm os inspetores locais sobre os modernos processos de ensino, entregam-se descansadamente ao método antigo, porém sempre prontos e indagando sempre da aproximação dos técnicos, a fim de preparar-lhes uma nova encenação de escola moderna. Recebem muito bem os inspetores condescendentes, gabam-lhe as boas maneiras, fazem alusões a sua fina educação, mas queixam-se amargamente daqueles que procuram afastá-los dos processos antigos, divorciá-los da rotina, chegam mesmo a lançar a pecha de grosseiros, por mais delicados que sejam. Para evitar aleivosas calúnias, adotou esta inspetoria o alvitre de fazer-se acompanhar em suas visitas técnicas pelo inspetor escolar e, na falta deste, por pessoas gratas da localidade visitada, as quais testemunham a maneira urbana e delicada com que exijo a transformação dos velhos processos nesse que a reforma estatuiu. São estas, exmo. sr., as impressões que tenho recebido ao empenhar-me na remodelação das escolas isoladas do Estado. Saúde e 
fraternidade. (Minas Gerais, Relatório de Inspeção, Uberabinha, 18 de maio de 1909)

Nas avaliações que faziam para dar conta do sucesso ou do fracasso de suas intervenções, os inspetores colocam em cena uma questão crucial: a capacidade do professor de imitar as práticas exemplares que lhes eram dadas a ver nas aulas que eram ministradas pelos inspetores dependia do domínio de um repertório prévio de base, que só um processo de formação docente, paralelo ou prévio, poderia assegurar.

A propósito, o artigo publicado pelo inspetor Alceu Souza Novaes, no jornal Lavoura e Comércio, registra as dificuldades relacionadas à falta de conhecimento dos professores quanto aos métodos e processos de ensino e às matérias do programa. Ele prescreveu o remédio para a solução do problema:

Fica muitas vezes o inspetor técnico a lecionar em uma escola as matérias do programa, esforçando-se para fazer compreender ao professor como se devem expor as lições "pelo método intuitivo tendo como base o sistema simultâneo", para, no fim de 10 ou 12 dias de assistência, deixar a escola nas mesmíssimas condições, pois, à parte a matéria que serviu de modelo, nada mais os alunos aprenderão. [...] O remédio, talvez o único remédio para o caso, seria seguir o estado de Minas o exemplo de São Paulo: chamar os professores por turmas a Belo Horizonte, mantê-los lá durante um ano a estudar o programa e, findo este prazo, submeter a exames os professores, sendo excluídos aqueles que neste tempo não se tenham tornado proficientes ao menos quanto ao conhecimento das matérias a lecionar. Até que essa idéia torne-se triunfante, mau grado a boa vontade dos inspetores e o seu esforço, haverá de se ter por muito tempo ainda professores para quem o técnico será simplesmente fiscal, sendo nulo todo o trabalho de assistência. (Jornal Lavoura e Comércio. Uberaba, quintafeira, 23 jun. 1910, p. 1)

Ao referenciar o modelo escolar paulista, o inspetor propõe o controle da administração central sobre a qualificação docente e argumenta que, caso contrário, a assistência prestada pelos técnicos seria nula, apesar da boa vontade dos inspetores e seu esforço e das aulas exemplares dadas por eles.

Na lógica que presidiu a Reforma de 1906, o bom funcionamento do serviço de inspeção dependia de um modelo de intervenção pedagógica no qual a arte de ensinar é prescrita como boa imitação de modelos, dados a ver em práticas exemplares (Carvalho, 2001). A análise sugere, entretanto, a possibilidade de que a instituição da inspetoria técnica, compreendida como dispositivo de formação de professores, começasse a evidenciar seus limites na consecução dos objetivos que lhe foram conferidos no âmbito das iniciativas da referida reforma.

No relatório apresentado ao presidente do Estado em 1918, por exemplo, o secretário do Interior aponta a necessidade de uma reforma da inspeção e apresenta um plano de reforma. Observa que "o ensino primário está pedindo uma fiscalização mais perfeita para ser melhor praticado" e ainda que o serviço de inspeção "está reclamando urgente modificação para que o ensino seja ministrado com mais proveito e eficiência" (Minas Gerais, Relatório do Secretário do Interior, 1918, p. 41-53).

Ao responder a esse reclamo, na Mensagem Presidencial do ano seguinte, o presidente Arthur Bernardes afirma que "a inspeção do ensino que tão bons resultados 
deu no princípio, está agora em franca decadência" (Minas Gerais. Relatório do Secretário do Interior, 1918. p. 41).

Seriam essas críticas ao sistema de inspeção indícios de uma mutação de maior monta na cultura pedagógica dos responsáveis pelas políticas de institucionalização e reforma escolar? A confirmar-se essa hipótese, uma mutação importante estaria sendo produzida no âmbito dos referenciais pedagógicos que norteavam tal reforma e prenunciavam, talvez, a emergência de outro modelo regulador dos processos de formação docente.

Atendo-se ao Estado de São Paulo, Carvalho (2000a; 2000b; 2001; 2002; 2011) tem sustentado que os referenciais pedagógicos que nortearam a política educacional paulista, nas primeiras décadas republicanas, são gradativamente solapados no decorrer da década de 1920 e cedem lugar a novos referenciais de algum modo comprometidos com a chamada Pedagogia da Escola Nova, que se difunde internacionalmente no período entre-guerras. Tais mudanças, sustenta a autora, redefiniriam as relações entre teoria e prática no campo dos saberes pedagógicos, com impacto na condução das políticas de remodelação escolar e de formação docente.

A redefinição do lugar da inspeção no âmbito das estratégias de remodelação escolar e de formação docente não é, do ponto de vista adotado neste trabalho, dissociável de mutações mais amplas nos referenciais pedagógicos que norteiam as políticas educacionais. Estaria também em curso em Minas Gerais um processo similar ao que vem sendo apontado por Carvalho relativamente a São Paulo? Essas questões suscitam novas perspectivas de análise para compreensão do processo histórico de institucionalização da escola primária no Brasil.

\section{Referências}

CARVALHO, Marta Maria Chagas de. A escola e a república. São Paulo: Brasiliense, 1989.

CARVALHO, Marta Maria Chagas de. Reformas da instrução pública. In: FARIA FILHO, Luciano Mendes; LOPES, Eliane Marta T; VEIGA, Cynthia Gonçalves. 500 anos de educação no Brasil. Belo Horizonte: Autêntica, 2000a, p. 225-251.

CARVALHO, Marta Maria Chagas de. Modernidade pedagógica e modelos de formação docente. Revista São Paulo em Perspectiva, São Paulo, v. 14, n. 1, 2000b, p. 111-120.

CARVALHO, Marta Maria Chagas de. A caixa de utensílios e a biblioteca: pedagogia e práticas de leitura. In: VIDAL, Diana Gonçalves; HILSDORF, Maria Lucia S. Brasil 500 anos: tópicas de história da educação. São Paulo: Edusp, 2001, p. 137-167.

CARVALHO, Marta Maria Chagas de. A escola e a república e outros ensaios. Bragança Paulista: Edusf, 2003.

CARVALHO, Marta Maria Chagas de. Livros e revistas para professores: configuração material do impresso e circulação internacional de modelos pedagógicos. In: CARVALHO, Marta Maria Chagas de; FREITAS, Marcos Cezar de; MOGARRO, Maria João; PINTASSILGO, Joaquim. (orgs.). História da escola em Portugal e no Brasil: circulação e apropriação de modelos culturais. Lisboa: Colibri/Centro de Investigação em Educação da Faculdade de Ciências da Universidade de Lisboa, 2006, p. 141-173.

CARVALHO, Marta Maria Chagas de. Pedagogia moderna, pedagogia da escola nova e modelo escolar paulista. In: CARVALHO, Marta Maria Chagas de; PINTASSILGO Joaquim 
(orgs.). Modelos culturais, saberes pedagógicos, instituições educacionais. São Paulo: Edusp/Fapesp, 2011, p. 185-212.

CERTEAU, Michel de. A invenção do cotidiano. Rio de Janeiro: Vozes, 1990.

FARIA FILHO, Luciano M. de. Dos pardieiros aos palácios: cultura escolar e urbana em Belo Horizonte na Primeira República. Passo Fundo: UPF, 2000.

ISOBE, Rogéria Moreira Rezende. Moldando as práticas escolares: um estudo sobre os relatórios da inspeção técnica do ensino do triângulo mineiro (1906-1911). São Paulo: PUCSP, 2004. 161f. Dissertação (Mestrado em Educação). Pontifícia Universidade Católica de São Paulo. Programa de Pós-Graduação em Educação.

ISOBE, Rogéria Moreira Rezende. Educação e civilização no sertão: práticas de constituição do modelo escolar no triângulo mineiro (1906-1920). São Paulo: PUCSP, 2008. 217f. Tese (Doutorado em Educação). Pontifícia Universidade Católica de São Paulo. Programa de Pós-Graduação em Educação.

MINAS GERAIS. Arquivo Público Mineiro. Relatório do secretário do Interior, 1907; 1909; 1912; 1913; 1914; 1918.

MINAS GERAIS. Arquivo Público Mineiro. Mensagem do presidente do Estado, 1907.

MINAS GERAIS. Arquivo Público Mineiro. Relatório de inspeção. Uberabinha, 18 maio, 1909.

Minas Gerais. Arquivo Público Mineiro. Relatório de inspeção. Prata. 24 fev., 1911.

MINAS GERAIS. Arquivo Público Mineiro. Relatório de inspeção. Prata, 13 mar., 1911.

MINAS GERAIS. Arquivo Público Mineiro. Relatório de inspeção. Uberaba, 5 maio, 1911.

MINAS GERAIS. Arquivo Público de Uberaba. Jornal Lavoura e Comércio. Uberaba, 23 jun., 1910.

VAGO, Tarcisio. M. Cultura escolar, cultivo de corpos: educação physica e gymnastica como práticas constitutivas dos corpos de crianças no ensino público primário de Belo Horizonte. Bragança Paulista: Edusf, 2002.

ROGÉRIA MOREIRA REZENDE ISOBE é doutora em educação pela PUCSP, professora adjunta do Departamento de Educação da Universidade Federal do Triângulo Mineiro - UFTM, pesquisadora do Núcleo de Estudos e Pesquisas em Política, História, Espaço, Educação e Sociedade (UFTM) e do Grupo de Pesquisas História Cultural da escola e dos saberes pedagógicos: impressos e modelos culturais - Unifesp.

Endereço: Rua Novo Horizonte, 900/103 - 38060-480 - Uberaba - MG - Brasil. E-mail: rogeriaisobe@gmail.com.

Recebido em 29 de junho de 2012.

Aceito em 30 de setembro de 2012. 